\title{
A EMERGÊNCIA DA ÉTICA SOCIAMBIENTAL EM SOCIEDADES PLURICULTURAIS EM BUSCA DO DESENVOLVIMENTO SUSTENTÁVEL
}

\author{
CHALLENGES TO RECONCILE THE ENVIRONMENTAL ASPECTS WITH \\ OTHER AREAS OF LAW
}

\author{
${ }^{1}$ Émilien Vilas Boas Reis \\ ${ }^{2}$ Stephanie Rodrigues Venâncio
}

\begin{abstract}
RESUMO
O presente artigo discorre sobre a emergência da ética socioambiental em sociedades pluriculturais, objetivando a compatibilização entre desenvolvimento econômico social e preservação da natureza, que corresponde à distribuição equitativa de riquezas e recursos naturais. Pretende-se a realização de uma crítica construtiva, orientadora de critérios mais equitativos para aplicação de diretrizes mínimas e básicas em busca da proteção ambiental mundial. Para tanto, serão abordadas questões como a construção do saber ambiental, a possibilidade de um novo olhar do homem sobre o meio em que vive e o desenvolvimento sustentável como projeto da ética socioambiental.
\end{abstract}

Palavras-chave: Ética, Meio ambiente, Sociedade, Sustentabilidade

\begin{abstract}
This paper discusses the emergence of environmental ethics in multicultural societies, aiming to reconcile economic and social development and preservation of nature, which is the equitable distribution of wealth and natural resources. the realization of constructive criticism, guiding more equitable criteria for application of minimum and basic guidelines in pursuit of global environmental protection is intended. Therefore, issues such as the construction of environmental knowledge will be addressed, the possibility of a new look of man on the environment they live in and the sustainable development and social and environmental ethics project.
\end{abstract}

Keywords: Ethics, Environment, Society, Sustainability

\footnotetext{
${ }^{1}$ Doutor em Filosofia pela Pontifícia Universidade Católica do Rio Grande do Sul - PUCRS, Rio Grande do Sul (Brasil). Professor pela Escola Superior Dom Helder Câmara - ESDHC, Minas Gerais (Brasil).

E-mail: $\underline{\text { mboasr@yahoo.com.br }}$

${ }^{2}$ Mestranda em Direito Ambiental e Desenvolvimento Sustentável pela Escola Superior Dom Helder Câmara ESDHC, Minas Gerais (Brasil). Assistente Judiciária pelo Tribunal de justiça de Minas Gerais - TJMG, Minas Gerais (Brasil). E-mail: ste_rodrigues06@yahoo.com.br
} 


\section{INTRODUÇÃO}

A ética socioambiental é um conceito que surgiu, aproximadamente, no de 1960, refletindo o cenário de discussões em torno da degradação ambiental mundial que se consolida a partir da Conferência das Nações Unidas para o Ambiente Humano, realizada em Estocolmo, Suécia, em 1972 e no Encontro de Belgrado, Iugoslávia, em 1975. (LIMA, 1999).

Atualmente, é inegável a crise ambiental experimentada pela humanidade. Diversos autores como Enrique Leff, Josafá Carlos de Siqueira, Renato Nalini e outros, descrevem a trajetória das relações de produção capitalistas dominantes no mundo e a consequente crise ecológica deflagrada. Apontam a ética socioambiental como a possível alternativa para a mudança de paradigma desejada em busca de novos princípios e valores para proteção da natureza e distribuição equitativa dos recursos.

A proteção expressiva do meio ambiente no Brasil pode ser observada através da Constituição da República de 1988. A revolucionária constituição elevou a mencionada proteção ao status de Direito Fundamental, assegurado pelo art. 225 que possui a seguinte redação: “Todos têm o direito ao meio ambiente ecologicamente equilibrado, bem de uso comum do poder e essencial à sadia qualidade de vida, impondo-se ao Poder Público e à coletividade o dever de defendê-lo e preservá-lo para as presentes e futuras gerações.”(BRASIL, 1988).

Entretanto, mesmo diante do amparo constitucional, o drama mundialmente presenciado é a escassez de recursos, como a própria água potável, poluição atmosférica, contaminação de mares, rios, aquecimento global, exclusão social e fome, consequências do modelo de produção capitalista preponderante.

Esse modelo visa exploração desmedida dos recursos e devastação do meio ambiente, objetivando primordialmente o lucro e a dominação econômica. Além dos recursos naturais, a produção cientifica intelectual, por muitos anos, também atendeu aos interesses capitalistas, visando à acumulação de capital.

As consequências das condutas humanas prejudiciais ao meio ambiente são foco constante de debates e críticas. No entanto, as próprias condutas humanas, além das meras consequências, passaram a ser objeto de questionamento, quanto a sua motivação e finalidade, principalmente no tocante as possíveis intervenções negativas que podem ser causadas a natureza. Assim, subsiste a necessidade se repensar a histórica interação homem/natureza, emergindo a possibilidade de compreensão de uma nova forma de se pensar a questão ambiental. 
Deste modo, o presente artigo objetiva analisar a possibilidade de inserção de uma mesma perspectiva ética socioambiental nas diversas sociedades pluriculturais, emersas em diferentes tradições e costumes.

A linha metodológica proposta será a Crítico-Metodológica, pois se busca a observância da realidade conflituosa na emergência de uma ética socioambiental pluricultural, objetivando a realização de uma crítica construtiva, orientadora de critérios mais equitativos para aplicação de diretrizes mínimas e básicas em busca da proteção ambiental mundial.

A princípio, a ética socioambiental surge como uma proposta de sobrevivência à crise e possibilidade de uma futura superação. Busca-se a harmonização do homem e de suas necessidades com a preservação da natureza.

Antigas concepções devem ser modificadas com a finalidade de frear o agravamento da crise e suas consequências. Essa visão ética propõe a construção de uma nova mentalidade que sobrepuje os tradicionais modelos de produção capitalistas vigentes. A ética socioambiental propõe a produção de um conhecimento sistêmico e abrangente, que envolva os diversos ramos conexos à problemática ambiental.

Nesse sentido, o saber ambiental, fundado nessa ética socioambiental, mostra-se como instrumento integrador da conduta humana ao meio ambiente. O objetivo dessa integração é a compatibilização entre desenvolvimento econômico social e preservação da natureza, que corresponde à distribuição equitativa de riquezas e recursos naturais. Para tanto, passa-se a discorrer sobre o saber ambiental e os desafios da ética socioambiental em busca da construção de uma visão holística da questão socioambiental.

\section{O SABER AMBIENTAL ENQUANTO INSTRUMENTO DA ÉTICA SOCIOAMBIENTAL}

A ética socioambiental apresenta-se como fundamento das ações humanas voltadas ao respeito para com o outro e para com a natureza, de modo a compatibilizar todas as ações individuais diante dos interesses coletivos e do meio em que se vive, constituindo verdadeiro saber pautado na relação indissociável entre homem e natureza e entre homem e sociedade.

De fato, a emergência de uma ética socioambiental impõe a alteração dos paradigmas atuais do conhecimento que degradam e excluem, objetivando, assim, a reintegração dos indivíduos e o cuidado para com o meio. A esse respeito, Édis Milaré destaca um "renascimento da ética", que envolve "as questões da vida, o destino do Planeta e a 
consolidação dos valores humanos em dimensões culturais e sociais”. (MILARÈ, 2011, p. 151).

É fato que o avanço da globalização e o desenvolvimento de novas tecnologias, principalmente a partir do Século XX, reforçaram a subjugação da natureza diante do racionalismo humano e dos direitos sociais diante do individualismo exacerbado, acarretando, cada vez de forma mais explícita, a degradação da natureza e a segregação social da parcela pobre da sociedade.

O ser humano, enquanto parte integrante do meio deve orientar-se por fundamentos e valores éticos que correspondam ao equilíbrio de suas atuações, de forma a assegurar o bem viver de todos.Nesse sentido, a ética socioambiental implica na reconsideração de valores, antes esquecidos, como a solidariedade, o respeito, o cuidado, impondo, assim, a construção de saberes alternativos na busca pela integração do conhecimento e pelo diálogo entre as culturas.

A emergência da ética socioambiental, dessa forma, visa alterar a visão de mundo do ser humano, fazendo-o compreender a essencialidade do meio ambiente ecologicamente equilibrado e a vital inter-relação com todos os indivíduos que o cercam.

Sobre o desafio da ética socioambiental e a necessidade de alteração da forma de ver o mundo, Maria de Fátima Schumacher Wolkmer e Nicole da Silva Paulitsch destacam:

\footnotetext{
A Ética Ambiental pode ser considerada como aquela que advém da necessidade de reexaminarmos nossos valores e princípios em razão dos problemas ambientais e à necessidade de compreendermos as razões que definem a relação do homem com a natureza. Não basta um despertar da consciência individual, necessitamos uma redefinição do quadro ético. (WOLKMER; PAULITSCH, 2011, p. 221).
}

A ética socioambiental, de fato, impõe verdadeira alteração dos paradigmas atuais do conhecimento que implicam na degradação do meio ambiente e na desconsideração dos problemas sociais, principalmente no que diz respeito à má distribuição de renda, violação de direitos fundamentais e desconsideração das minorias, em flagrante desrespeito à atual sociedade pluricultural.

As sociedades contemporâneas, de forma premente, necessitam de uma reintegração de valores éticos que acarretem na consideração das peculiaridades de cada indivíduo e comunidade, de forma a contribuir para a sadia qualidade de vida dos indivíduos e preservação do meio ambiente.

É através da atuação das empresas, da Administração Pública, por meio de políticas públicas efetivas e da participação popular, voltadas ao desenvolvimento sustentável e 
pautadas na ética socioambiental, que se verifica verdadeiro fundamento para a superação da crise ambiental.

Impõe-se, dessa forma, a alteração de postura de governos, empresas e indivíduos, com o intuito de contribuir para a sadia qualidade de vida de todos, de forma a atender os anseios de todas as comunidades, respeitando-se as diferenças e as implicações decorrentes das ações humanas frente ao meio ambiente.

Nesse sentido, a ética socioambiental apresenta uma postura crítica diante do atual desenvolvimento econômico que desconsidera as minorias e as questões ambientais, demandando, assim, um saber integrador, capaz de compatibilizar interesses individuais e coletivos e equilibrar a relação homem x natureza, conforme destaca Siqueira:

\begin{abstract}
Hoje, mais do que em outras épocas, é fundamental resgatar a visão holística da realidade, permitindo que a pessoa humana possa perceber as inter-relações existentes entre todas as manifestações de vida existentes na natureza, como também entre inúmeras mediações sociais que fazem parte da história cultural. Para tanto, é necessário um processo de reeducação para o holos, ou seja, para a visão de totalidade. (SIQUEIRA, 2009, p. 33).
\end{abstract}

De fato, o atual paradigma do conhecimento, pautado na racionalidade científica, apresenta-se como uma visão desintegradora dos laços sociais, eis que impõe, como principal objetivo do modelo de desenvolvimento econômico, o lucro e o incremento do mercado.

Tal modelo desenvolvimentista acaba por desconsiderar direitos fundamentais básicos previstos pelo texto constitucional, entre eles o direito à vida, à igualdade e à saúde.

Evidencia-se, assim, que o modelo atual de desenvolvimento econômico e a postura dos indivíduos desvinculados dos interesses comuns apresentam-se desgastados, diante da negativa das questões ambientais e sociais, que desvincula a existência humana do meio ambiente saudável, motivo pelo qual se passa a enfrentar crises econômicas, sociais e ambientais sem precedentes, que acabam por inviabilizar a existência humana com dignidade.

Dessa forma, denota-se uma verdadeira crise do conhecimento, em razão dos saberes negados, entre eles a sociologia e a ecologia, em uma verdadeira fragmentação do conhecimento, que acaba por ocasionar a perda da visão integradora do mundo.

A crise do conhecimento decorre, portanto, dessa negativa das questões sociais e ambientais, sendo certo que, nos dizeres de Eugène Enriquez: "os homens se voltam sobre sua esfera privada, sobre seu grupo de referência ou sobre sua etnia. Eles se tomam a si mesmos como ideal, apresentando um total individualismo que implica a predominância de pulsões e de interesses egoístas sobre qualquer outro tipo de investimento.” (ENRIQUEZ, 2001, p. 64). 
Ademais, ressalta-se que essa crise do conhecimento e, consequentemente, a crise ambiental, decorrem da perda dos valores fundamentais, entre eles o respeito e a solidariedade, acarretando uma verdadeira crise de identidade e desvinculação do meio em que vive, "exigindo uma mudança conceitual de paradigma no que tange à concepção de bemestar do homem, à questão das gerações futuras e à consideração da natureza como detentora de um valor intrínseco a ser respeitado." (WOLKMER; PAULITSCH, 2011, p. 221).A esse respeito, Celso Antônio Pacheco Fiorillo destaca que a visão atual do homem para com a natureza funda-se em uma ideia de poder e de "satisfação das necessidades humanas". (FIORILLO, 2012, p. 70).

A crise do conhecimento, que também implica na crescente desconsideração da natureza, que passa a ser entendida como mero reservatório das necessidades humanas, demanda a reintegração culturas e valores éticos, através do saber ambiental, que resgata os saberes anteriormente negados, envolvendo, assim, em um verdadeiro ciclo, os anseios das minorias.

Ulrich Beck destaca a crise ambiental frente ao individualismo exacerbado e ao desconhecimento das questões que foram relegadas pelo desenvolvimento econômico desenfreado, onde a humanidade passa a ser vista como uma força destrutiva.

\begin{abstract}
A oposição entre natureza e sociedade é uma construção do século XIX, que serve ao duplo propósito de controlar e ignorar a natureza. A natureza foi subjugada e explorada no final do século XX e, assim, transformada de fenômeno externo em interno, de fenômeno predeterminado em fabricado. Ao longo de sua transformação tecnológico-industrial e de sua comercialização global, a natureza foi absorvida pelo sistema industrial. (BECK, 2011, p.9).
\end{abstract}

É diante dessa crise do conhecimento e frente aos anseios de uma ética socioambiental, que o saber ambiental emerge como um saber integrador, que busca trazer do campo das externalidades as questões ambientais e sociais antes negadas pelo paradigma atual do conhecimento.

Para tanto, Maria de Fátima Schumacher Wolkmer e Nicole da Silva Paulitsch asseveram que "a perspectiva ambiental consiste em um modo de ver o mundo no qual se evidenciam as inter-relações e a interdependência dos diversos elementos na constituição e manutenção da vida". (WOLKMER; PAULITSCH, 2011, p. 214).

Impõe-se, portanto, o saber ambiental, que implica na consideração do local sobre o global, com a emergência dos saberes subjugados, diante da crescente exclusão das minorias e 
desrespeito com as culturas e identidades diferentes, nos termos apresentados por Henrique Leff:

\begin{abstract}
A crise ambiental e a crise do saber surgem como a acumulação de "externalidades" do desenvolvimento do conhecimento e do crescimento econômico. Surgem como todo um campo do real negado e do saber desconhecido pela modernidade, reclamando a "internalização" de uma "dimensão ambiental" através de um "método interdisciplinar", capaz de reintegrar o conhecimento para apreender a realidade complexa. (LEFF, 2000, p. 19).
\end{abstract}

Não se olvida que as questões ambientais e sociais foram desconsideradas diante do inerente desenvolvimento econômico, primordialmente a partir da Revolução Industrial, de modo que o saber ambiental, agora, como forma de resgate e proteção dos valores esquecidos, implica na integração do "saber negado", diante do desconhecimento da finitude dos recursos naturais. (LEFF, 2000, p. 19).

De fato, a alteração dos paradigmas atuais do conhecimento decorre da necessária consideração das questões sociais e ambientais, diante das tragédias ocorridas, conforme sustenta Siqueira:

\begin{abstract}
Diante do agravamento da crise ambiental em que vivemos e das sérias consequências na vida das pessoas e da sociedade, faz-se necessário uma mudança de valores em prol de um mundo mais sustentável para as gerações presentes e futuras. Tudo indica que só sairemos da crise em que estamos mergulhados se optarmos pelos caminhos da ética. É necessária uma mudança de hábitos injustos e incorretos, para que possamos construir novos costumes que sejam socialmente mais adequados às mudanças ambientais, que certamente ocorrerão em um futuro próximo. (SIQUEIRA, 2009, p. 11).
\end{abstract}

Para tanto, o saber ambiental, através da interdisciplinaridade, pretende reintegrar saberes, passando de uma visão fragmentada para uma visão holística do mundo, que considera a diferença, o novo e o necessário como formas de adequação da vida.

O ser humano, através dessa visão integradora, passa a ver o meio ambiente e o outro como essenciais à existência dele, eis que sua natureza é essencialmente social e interligada com a natureza.Sobre a interdisciplinaridade como meio de atuação do saber ambiental, Enrique Leff sustenta:

O saber ambiental está transitando, assim, do desafio da interdisciplinaridade para a abertura de um diálogo dos saberes. (...) A interdisciplinaridade ambiental estabelece a transformação dos paradigmas estabelecidos do conhecimento para internalizar um saber ambiental. (LEFF, 2000, p. 30). 
A interdisciplinaridade, portanto, apresenta-se como a busca pela integração do conhecimento, pela consideração da diversidade e pelo respeito para com as diferenças e para com o meio em que se vive de forma a destacar a importância da visão holística do mundo, compatibilizando as ações humanas em relação ao meio ambiente.

Daí porque emerge a importância da ética socioambiental, diante da frequente desconsideração do meio ambiente e das demandas sociais, que se vêem subjugadas diante da racionalidade científica dominante, potencializada pela globalização que de forma mais frequente fratura laços sociais, impõe a desconsideração das diferenças e rejeita a proteção efetiva da natureza, conforme destaca Leff:

O processo de globalização econômica organiza rituais para venerar o deusmercado, para pedir-lhe maiores colheitas de crescimento sustentável, sem considerar que é esse crescimento econômico, regido pelas leis do mercado e por uma racionalidade do lucro de curto prazo (leis humanas sujeitas ao poder entre humanos), que se produz os ritmos crescentes de extração e transformação de recursos naturais, de matéria e energia sujeita às leis da entropia. (LEFF, 2000, p. $32)$.

O saber ambiental, portanto, como instrumento da ética socioambiental, implica na inter-relação sociedade-natureza, com o respeito às culturas e aos saberes tradicionais, que se apresentam como imperativos vitais para as sociedades contemporâneas, que se veem vinculadas ao meio onde vivem, em um verdadeiro sentimento de pertença.

De fato, a exclusão social e, consequentemente, a miséria, não podem mais ser entendidas como causas da degradação ambiental, mas sim, efeitos de um desenvolvimento econômico que desconsidera as diferenças culturais e a biodiversidade da natureza.

Enrique Leff sustenta a essencial integração das culturas e saberes, destacando, assim, que "a gestão ambiental num regime democrático implica na gestão participativa da população no processo de produção. A encruzilhada pela sustentabilidade é uma disputa pela natureza e uma controvérsia pelos sentidos alternativos do desenvolvimento sustentável". (LEFF, 2000, p. 45).

Ainda sobre a compatibilização das atuações humanas em respeito ao meio que se vive, Leff assevera "que a sustentabilidade tenha como condição inevitável a participação dos atores locais, de sociedades rurais e comunidades indígenas, a partir de culturas, seus saberes e suas identidades". (LEFF, 2000, p. 45).

Assim, ressalta-se a importância de se reintegrar os valores humanos que há muito se encontram perdidos, diante do imprescindível pensar do homem enquanto ser social, inserido no meio ambiente essencial à existência dele. 
Nesse sentido, o saber ambiental apresenta-se como verdadeiro instrumento da ética socioambiental, diante da necessária alteração de paradigmas, com a reintegração de valores que dizem respeito à consciência da vitalidade do meio ambiente e importância da diversidade cultural.Para melhor compreender a visão integradora de mundo pretendida pela ética socioambiental, passa-se a discorrer sobre a possibilidade de um novo olhar do homem sobre o meio em que vive.

\section{UM NOVO OLHAR PARA A BIODIVERSIDADE}

O modelo econômico capitalista, preponderante dentre os modelos de desenvolvimento econômicos vigentes, demonstrou-se ser incompatível com a preservação racional do meio ambiente.Em busca da maximização dos lucros e do aumento exacerbado da produção, o homem serviu-se da natureza de forma abusiva, desconsiderando os processos naturais de recomposição dos biomas e ecossistemas.

Josafá Carlos de Siqueira ressalta que a atual conjuntura não é apenas fruto da mencionada crise ecológica, mas resultado da soma dessa crise à crise econômica, também vivida mundialmente. Contudo, a denominada crise ecológica, aparentemente mais branda pelos seus lentos efeitos, dificilmente é notada pela maioria das pessoas (SIQUEIRA, 2009).

O mau uso dos recursos naturais desarmonizou o complexo sistema de relações entre os seres vivos tornando-se insustentável. A biodiversidade presente em nosso planeta (flora e fauna) serviu apenas para alimentar o sistema capitalista de forma indiscriminada.

Não se pensou no esgotamento dos recursos e na extinção espécies, mas apenas no potencial produtivo do sistema, com suas fabricas, indústrias e usinas. Neste contexto, Josafá Carlos de Siqueira discorre sobre o uso irracional do meio ambiente em prol de uma racionalidade produtiva antiética devastadora dos biomas: "A racionalidade política e econômica se distancia cada vez mais da racionalidade axiológica, fazendo com que a biodiversidade seja contemplada não a partir de uma ética de valores, mas numa perspectiva utilitarista e consumista." (SIQUEIRA, 2009, p.57).

O desenvolvimento científico, que apenas quantifica a biodiversidade e promove o mapeamento dos recursos naturais, criando um diagnóstico da devastação, não é suficiente, como também não o são os avanços tecnológicos que busquem apenas a minimização dos impactos ambientais, mas que mantenham como finalidade a continuidade do processo de exploração. 
Deve haver a mudança dos pilares sustentadores do modelo de desenvolvimento econômico preponderante, em busca de novos valores, princípios e diretrizes orientadoras de uma postura mais ética do homem diante do planeta. Para tanto, Siqueira discorre sobre essa nova perspectiva da biodiversidade, vinculada à realidade social, necessária para própria sobrevivência das diversas formas de vida:

\begin{abstract}
A biodiversidade, nos últimos anos, passou a ser tratada não apenas como um suporte essencial da vida sobre o planeta ou como uma questão puramente ecológica e cientifica, mas também agregado outras dimensões, como valor econômico, reserva de futuro, biotecnologia e até mesmo como geopolítica de estratégias e conflitos territoriais. (SIQUEIRA, 2009, p. 58)
\end{abstract}

Não se pode esquecer que a discussão acerca da importância e preservação dessa biodiversidade não atinge apenas o âmbito local e interesses particulares. As consequências do modelo econômico capitalista e os impactos ambientais decorrentes desse atingem todos os ecossistemas e biomas de alguma maneira. Josefá deixa claro essa mudança de pensamento ao afirmar que:

\footnotetext{
Se até o momento nossas preocupações foram voltadas para a preservação de biomas e espécies de nossos ecossistemas locais, agora, com as mudanças climáticas, temos que pensar nessa questão de maneira mais global e imediata, pois os efeitos negativos afetarão todos os nossos biomas mundiais. (SIQUEIRA, 2009, p. 63)
}

A mudança de concepções quanto ao tratamento dispensado ao meio ambiente e a nova ética socioambiental emergente se contrapõe ao cenário de crise mundial. Desta forma, não basta que a mudança de comportamento ocorra em âmbito local. Preservar pontualmente a natureza, desconsiderando seu aspecto global e sistêmico, seria desconsiderar as infinitas relações entres os ecossistemas e todas as formas de vida.

Siqueira explicita a necessidade da preservação no seu aspecto global ao mencionar que:

\footnotetext{
Eticamente não podemos pensar a conservação local e global separadamente, porém, ao contrário, temos que buscar alternativas locais e globais numa escala de tempo menor, a fim que possamos garantir a sobrevivência de muitos biomas e espécies, sobretudo daquelas que já se encontram vulneráveis pelos sucessivos e devassos processos de destruição da natureza. (SIQUEIRA, 2009, p. 63).
}

Entretanto, encontramos um claro obstáculo que consiste na dificuldade em convergir posicionamentos emersos na diversidade cultural mundial em prol da mesma causa ambiental. De fato, o processo de globalização e o cenário de sociedades pluriculturais dificultam a emergência de uma ética socioambiental consistente e virtuosa. Siqueira deixa 
clara a existência de um conflito entre o discurso ético e as posturas e práticas dos compromissos assumidos pelos países. (SIQUEIRA, 2002).

Dificilmente, são assumidas posturas em prol do meio ambiente que possam frear o desenvolvimento econômico e desacelerar a produção capitalista.Entre o desejo de prosperar a economia e desenvolver o país, deve prevalecer o anseio de se prezar pela vida, pois sem está, nenhum desenvolvimento ou riqueza material faz o menor sentido.

O mesmo autor é preciso ao destacar que: "Uma ética ambiental, que pretende ser um referencial para as ações globais e locais não pode conviver com essa esquizofrenia entre as boas intenções teóricas e as práticas contraditórias.” (SIQUEIRA, 2002, p. 77).

Devem-se evitar os discursos meramente moralistas a respeito da preservação ambiental. A harmonização das diferentes sociedades culturais deve ocorrer em busca da construção de uma ética socioambiental pluricultural que objetiva a reintegração dos valores fundamentais, tais como: a solidariedade, o cuidado e o respeito à diferença.

Para obter essa harmonização, a ética socioambiental demanda a construção de um projeto pautado no desenvolvimento sustentável capaz de reduzir os impactos ambientais e minimizar o quadro de exclusão social.

\section{O DESENVOLVIMENTO SUSTENTÁVEL COMO PROJETO DA ÉTICA SOCIOAMBIENTAL}

A crescente desconsideração das questões sociais, principalmente no que diz respeito à diversidade de culturas, às minorias cada vez mais anuladas e os saberes tradicionais esquecidos, decorrem dos "modelos socioambientais insustentáveis", implicando no aumento das desigualdades sociais e na degradação da natureza, em um crescente sentimento de dissociação entre o homem e o meio em que vive. (SIQUEIRA, 2009, p. 160). A esse respeito, Hans Jonas (2012) destaca a crise civilizatória decorrente do modelo econômico capitalista, que desconsidera as implicações ambientais e sociais das atuações humanas.

Não se olvida que o avanço tecnológico e econômico implica na melhoria da qualidade de vida do ser humano, notadamente no que tange à evolução de saberes que importem no desenvolvimento dos meios essenciais à vida humana.

No entanto, este avanço deve, primordialmente, pautar-se no cuidado com o meio, internalizando as questões ambientais e sociais, sob pena de frustrar as próprias expectativas da sociedade, que acaba por ver desconsiderados valores básicos de sua existência, como a dignidade, a integridade e o respeito. 
Não é plausível, assim, considerar um desenvolvimento econômico que traga consigo misérias e violências, voltado, tão somente, para a lógica mercadológica da riqueza e progresso, em uma patente desconsideração das minorias e degradação do meio ambiente.

Observa-se, dessa forma, que a crise civilizatória das sociedades contemporâneas decorre do desenvolvimento econômico atual, pautado na racionalidade científica,que nega as minorias, os saberes tradicionais e a natureza, que passam a ser compreendidos como meras externalidades frente à lógica racional do mercado.

Em oposição a tal paradigma desenvolvimentista, passa-se a compreender que a expressão desenvolvimento sustentável não pode ser concebida como a compatibilização, no plano ideal, das ações humanas e do meio ambiente. Não é crível que se afirme um desenvolvimento sustentável apenas pelo fato de não degradar a natureza e não subjugar os mais fracos, nos termos evidenciados por Leonardo Boff:

\footnotetext{
$\mathrm{Na}$ maioria dos casos a sustentabilidade apresentada é mais aparente do que real. (...) É por esta razão que a utilização política da expressão desenvolvimento sustentável representa uma armadilha do sistema imperante: assume os termos da ecologia (sustentabilidade) para esvaziá-los e assume o ideal da economia (crescimento/desenvolvimento), mascarando, porém, a pobreza que ele mesmo produz. (BOFF, 2012, p. 40/46).
}

De fato, por desenvolvimento sustentável deve-se compreender como "a tendência dos ecossistemas ao equilíbrio dinâmico, à cooperação e à coevolução, e que responde pelas interdependências de todos com todos, garantindo a inclusão de cada um, até dos mais fracos”. (BOFF, 2012, p. 45).

A sustentabilidade não implica, somente, no não degradar e no não excluir, mas sim no equilíbrio entre o desenvolvimento econômico-social e o meio em que se vive, com a integração de todos de forma circular, sem distinção cultural e espacial, nem tampouco impondo à natureza praticas insustentáveis, tudo isto com o intuito de efetivar o respeito à diferença e a solidariedade em relação aos mais fracos, de forma que restem a todos assegurado o bemestar e a dignidade.

Destaca-se que as sociedades contemporâneas apresentam um modelo de desenvolvimento econômico-social pautado na acumulação de riqueza e na desconsideração da diversidade cultural, implicando, consequentemente, na crescente degradação da natureza e exclusão social, que se agravam diante da imposição do atual modelo econômico de produção e consumo, que se direcionam basicamente aos interesses das maiorias.

Fraçois Ost, ao destacar a apropriação e a transformação da natureza pelo homem e a natureza dele enquanto ser social sustenta a representação holística do universo, afirmando 
que "o homem não tem existência fora do grupo, do mesmo modo que o grupo humano apenas pode ser compreendido no quadro da sua pertença à natureza.” (OST, 1995, p. 31).De fato, não há progresso sem desenvolvimento conjunto, global. Uma sociedade que desconsidera a natureza e o outro não pode se denominar desenvolvida.

Nos dizeres de Leonardo Boff, o sistema capitalista, que propiciou inúmeras comodidades aos seres humanos, com a melhora das condições de vida e de saúde, apresentase como um modelo que esgotou seus benefícios e virtudes, passando a ser visto como um modelo "altamente dilacerador dos laços sociais e destrutivo das bases que sustentam a vida." (BOFF, 2012, p. 42).

A esse respeito, assevera-se a premente necessidade de alteração dos paradigmas atuais do conhecimento, que importem na reconsideração do meio ambiente e da pluralidade de culturas, congregando todos os indivíduos, na persecução do bem-estar social e na retomada de valores intrínseco e essenciais a existência humana, entre eles a solidariedade, o cuidado e o respeito, tanto para com o meio em que se vive como para com o outro diferente.

Assim, embora se fale em uma sustentabilidade apenas aparente, torna-se necessário voltar os olhos para as questões que dizem respeito ao meio ambiente e à sociedade. Nesse sentido, Boff destaca:

Não é correto, não é justo nem ético que, ao buscarmos os meios para a nossa subsistência, dilapidemos a natureza, destruamos biomas, envenenamos os solos, contaminemos as águas, poluamos os ares e destruamos o sutil equilíbrio do Sistema Terra e do Sistema Vida. Não é tolerável eticamente que sociedades particulares vivam à custa de outras sociedades ou de outras regiões, nem que a sociedade humana atual viva subtraindo das futuras gerações os meios necessários para poderem viver decentemente. (BOFF, 2012, p. 64).

Nesse sentido, a ética socioambiental emerge como motor para a alteração da atual visão de mundo, de forma a integrar todos os seres humanos junto ao meio, nos termos destacados por Maria Helena Soares Bentes:

É, portanto, através da nova Ética delineada por Jonas, diversa da Ética tradicional, que será possível compreender a relação homem $\mathrm{x}$ natureza, privilegiando os elementos essenciais do antropocentrismo clássico, mas observando também os componentes da biosfera e da biologia. Cuida-se, assim, de um novo olhar que irá pensar a idéia de vida inserta na própria formulação do imperativo ético. (BENTES, 2012, p. 176).

De fato, não podemos compreender a existência humana desvinculada do meio ambiente, nem tampouco conceber a vivência do indivíduo desconectada do seu contato e 
respeito com o outro, que lhe é diferente, porquanto ser social que necessita dos demais para viver em harmonia.

A sustentabilidade, portanto, pautada na ética socioambiental integradora dos valores essenciais à existência humana com dignidade, entre eles o sentimento de pertença do indivíduo para com o meio onde vive, impõe a compatibilização entre as ações humanas e a utilização dos recursos naturais, em atenção aos limites da natureza.

Maria de Fátima Schumacher Wolkmer e Nicole da Silva Paulitsch asseveram, a esse respeito, que a sustentabilidade implica "em soluções economicamente viáveis de satisfação de necessidades, além de relações sociais que permitam qualidade adequada de vida para todos." (WOLKMER; PAULITSCH, 2011, p. 219).

Assim, evidencia-se o indispensável equilíbrio entre o homem e a natureza, entre os interesses individuais e coletivos, na busca pelo bem-estar social, materializado na existência digna de todos, conforme assevera Leonardo Boff:

\begin{abstract}
Não é possível um impacto ambiental zero, pois toda geração de energia cobra algum custo ambiental. De mais a mais, é irrealizável, em termos absolutos, dada a finitude da realidade e os efeitos da entropia, que significa o lento e irrefreável desgaste de energia. Mas pelo menos o esforço deve orientar-se no sentido de proteger a natureza, de agir em sinergia com seus ritmos e não apenas não fazer-lhe mal; importante é restaurar sua vitalidade, dar-lhe descanso e devolver mais do que dela temos tirado para que as gerações futuras possam ver garantidas as reservas naturais e culturais para o seu bem-viver. (BOFF, 2012, p. 40).
\end{abstract}

A ética socioambiental, de fato, mostra o caminho a ser percorrido pelo ser humano na busca pelo bem-estar social, pautado na valorização da vida e da relação do homem com a natureza, sendo o indivíduo entendido como parte integrante do meio e não alheio a ele.

Josafá Carlos de Siqueira destaca que o desafio ético está, assim, na busca pelo resgate de valores, entre eles a solidariedade, o cuidado e o respeito, que possam equilibrar a relação homem x natureza, bem como compatibilizar a diversidade de culturas, em uma crescente integração entre desenvolvimento econômico-social e proteção da natureza, impondo-se, necessariamente, um desenvolvimento sustentável para a preservação da vida humana com dignidade (SIQUEIRA, 2009).

A esse respeito, a ética socioambiental demanda uma reintegração de saberes e valores que importem na consideração e no respeito à pluralidade de identidades.

Passa-se assim a discorrer sobre as sociedades pluriculturais e seus aspectos preponderantes, buscando a superação das possíveis diferenças culturais em busca da prevalência da proteção ambiental. 


\section{DIFERENÇAS E DESAFIOS DAS SOCIEDADES PLURICULTURAIS}

O ser humano por sua natureza é composto por particularidades, diferenças e variedades. Trata-se de um ser inconstante, dotado de vontades e desejos, manifestados das mais diversas formas. Renato Nalini elucida essa diversidade ao dizer que: "A homogeneidade não é própria da criatura humana, senão dos formigueiros. Ninguém pode alentar o desejo de uma coincidência dos modos de pensar." (NALINI, 2003, p. 272).

É justamente nessa diversidade que reside o maior desafio para implementação de uma ética socioambiental global. De fato, pensara homogeneidade do pensamento ambiental é praticamente impossível.Entretanto, podemos idealizar a criação de critérios mínimos para preservação ambiental.

Renato Nalini assegura que a criação desses critérios, chamados por ele de "consenso", só seria possível através do diálogo. A ausência desse entendimento faria com que a possível experiência democrática em busca desta ética terminasse em caos ou no autoritarismo (NALINI, 2003).

Independente da cultura e das práticas tradicionais de uma sociedade, algo é certo: a relação causa e consequência dos comportamentos humanos diante do meio ambiente é concreta e real.

Ações humanas que poluam, devastem e menosprezem a natureza são maléficas, não apenas para povos locais que a cometam, mas para toda a humanidade, inclusive para as gerações futuras que habitarão a terra. A questão ambiental deve ultrapassar os interesses meramente econômicos e locais. Trata-se da própria existência do ser humano e as demais formas de vida.

Ana Maria D'Ávila Lopes discorre sobre o multiculturalismo também chamado de pluralismo cultural ou cosmopolitismo, propondo que este seria a busca pelo reconhecimento e respeito à diversidade cultural existente em todas as sociedades. As sociedades contemporâneas seriam formadas por diversas expressões de cultura e tradição. Cada uma delas apresentaria suas particularidades, ideologias, correntes políticas e princípios. A esse respeito, a autora descreve o multiculturalismo como a ideologia que possibilidade a coexistência de culturas diversas, em um mesmo espaço, com base no principio da tolerância e do respeito à diferença. (LOPES, 2012).

Coexistir, neste caso, não significa impor o pensamento predominante ou desprezar as minorias. $\mathrm{O}$ real respeito às diferenças determina que qualquer tomada de decisão, não 
poderá menosprezar as culturas minoritárias, respeitando Direitos Fundamentais como: a vida, a liberdade, a igualdade e a dignidade da pessoa humana.

Para tanto, o Estado possui o relevante papel de promover o diálogo entre todas as expressões culturais a fim de evitar o desprezo de qualquer minoria. Nesse sentido, a autora Ana Maria D’Ávila Lopes esclarece que: “Constitui, portanto, tarefa impostergável de todo Estado que se autotitule democrático fomentar o diálogo entre as maiorias e as minorias da sua sociedade, por meio da regulação da escola, da mídia e do Direito, de forma a incluir a participação efetiva das minorias.” (LOPES, 2012, p.3).

É desta forma que a questão ambiental e a possibilidade da emergência de uma ética global devem ser analisadas. O diálogo mencionado é necessário também no que diz respeito ao meio ambiente, levando-se em consideração todas as formas de manifestação cultural. Porém, também neste caso, critérios devem ser observados para que não ocorra o menosprezo de nenhuma minoria.No que diz respeito à questão ambiental, essas diretrizes apresentam-se indiscutivelmente aliadas às concepções básicas, tais como: sadia qualidade de vida e dignidade da pessoa humana.

A busca por semelhanças entre culturas, na tentativa de se alcançar a harmonização da proteção ambiental, deve ser direcionada, inicialmente, a valores primitivos comuns e universais, como o próprio extinto de sobrevivência dos seres vivos.

A emergência de uma ética socioambiental global deve ser sustentada por direitos compartilhados pelas culturas como o direito a vida e ao meio ambiente ecologicamente equilibrado.

O Estado possui o dever de promover o diálogo e a discussão necessária entre todos envolvidos e atingidos pelas práticas ambientais vigentes. A diversidade das culturas existentes deve implicar na crescente consideração do homem enquanto ser social que depende do outro para sua sobrevivência.

A crise de conhecimento, que implica na crise ambiental, também acarreta a desconsideração das minorias, que acabam subjugadas e desconsideradas diante do inerente desenvolvimento econômico voltado, tão somente, para o acumulo de riquezas e otimização do mercado de consumo.Nesse sentido, verifica-se que a diversidade de identidades mostra-se cada vez mais desconsiderada diante da lógica mercadológica que visa somente o lucro e o consumismo exacerbado. 
Não se torna crível, que a pobreza e a exclusão social sejam entendidas como causas da degradação ambiental, mas sim, são consequências, junto com a desconsideração dos limites da natureza.A esse respeito, verifica-se que as culturas que afastam o consumismo e a lógica capitalista acabam esmagadas pela denominada globalização, de forma que, aquele que não consome, não faz parte do mercado e, por isso, não é carecedor de atenção e respeito por parte de governos e empresas, acarretando verdadeira crise social, nos termos asseverados por Leonardo Boff:

\begin{abstract}
A causa principal da crise social se prende à forma como as sociedades modernas se organizam no acesso, na produção e na distribuição dos bens da natureza e da cultura. Essa forma é profundamente desigual, porque privilegia as minorias que detêm o ter, o poder e o saber sobre as grandes maiorias que vivem do trabalho. (BOFF, 2003, p. 14).
\end{abstract}

A ausência de Políticas Públicas voltadas à parcela carente da sociedade ressalta a desconsideração das minorias, de forma que a crise habitacional, na saúde e as questões de segurança pública e conflitos internacionais mostram-se como agravantes do quadro social e ambiental atual, diante do crescente sentimento de desvinculação do homem com o meio onde vive e com o outro que convive.

Leonardo Boff, ao indagar a possibilidade da convivência harmoniosa entre os indivíduos, destaca a necessidade de uma ética planetária que enfrente, de forma efetiva, as questões da injustiça social e degradação do meio ambiente, de forma a alterar os caminhos traçados pelo ser humano, que hoje implicam, necessariamente, na degradação do meio ambiente e na desconsideração dos problemas sociais. (BOFF, 2003).

A emergência dessa ética planetária sugerida pressupõe o diálogo entre culturas e o respeito às diferenças, implicando na participação efetiva de todos na construção das diretrizes e valores basilares da ética socioambiental, contemplando todas as formas de expressão cultural, minoritárias e majoritárias, na consecução de um desenvolvimento sustentável que assegure a existência digna de todos.

\title{
6 CONCLUSÃO
}

A ruptura dos laços de solidariedade entre os indivíduos e do sentimento de pertença do ser humano em relação à natureza decorrem da crise de conhecimento alavancada pelo modelo de desenvolvimento econômico que desconsidera as diferenças e impõe uma racionalidade que exclui a diversidade e desconsidera a natureza. Nesse sentido, as ações 
humanas voltam-se ao meio como verdadeira força destrutiva, implicando a deterioração da natureza e a exclusão social, em uma verdadeira crise de civilização.

De fato, a crise civilizatória decorre da desconsideração das minorias e da imposição dos modelos de desenvolvimento e de consumo que acabam por degradar o meio ambiente e excluir parcela da sociedade, tanto por questões econômicas quanto culturais.

Diante do atual quadro de tensão, os direitos fundamentais, principalmente no que diz respeito ao meio ambiente ecologicamente equilibrado, mostram-se relegados, de forma que o indivíduo vive em crescente insegurança.

A violação dos direitos fundamentais, notadamente no que diz respeito à degradação do meio ambiente e à segregação social, revela o declínio dos paradigmas atuais de desenvolvimento, impondo-se o necessário reconhecimento do direito ao meio ambiente ecologicamente equilibrado e da imprescindível proteção da natureza, diante das ações antropogênicas negativas.

A compreensão, portanto, da natureza enquanto meio essencial á existência humana implica no avanço de práticas que assegurem os direitos fundamentais constitucionalmente garantidos, entre eles a sadia qualidade de vida e o bem-estar de todos.

A crescente degradação do meio ambiente e a segregação social decorrem dos paradigmas atuais do conhecimento, que se fundam primordialmente na acumulação de riquezas e na desconsideração das diferenças.

As sociedades contemporâneas, embora vivenciem evoluções econômicas e tecnológicas nunca antes observadas, demonstram completo desleixo e desconsideração diante das questões ambientais e sociais.Nesse sentido, impõe-se verdadeira alteração do atual paradigma dominante de conhecimento, através do saber ambiental, tanto por parte da sociedade civil, quanto de governos e empresas, na busca pela implantação de um modelo de desenvolvimento sustentável que implique na visão holística do mundo, de forma a integrar a diferença e consolidar a compatibilização entre as ações humanas e o meio ambiente.

A ética socioambiental direciona-se verdadeiramente à implementação efetiva do modelo de desenvolvimento sustentável voltado à harmonização entre as diversas culturas e a preservação do meio ambiente, de forma a assegurar que a conduta humana esteja pautada no entendimento de que todos os seres humanos são parte integrante do meio, sem qualquer distinção, ainda que diferentes. 


\section{REFERÊNCIAS}

BECK, Ulrich. Sociedade de risco rumo a uma nova modernidade. Tradução: Sebastião Nascimento. São Paulo: Editora 34, 2011.

BENTES. Hilda Helena Soares. Prometeu Liberto: nova ética para o homem da técnica segundo Hans Jonas. Revista Veredas do Direito: Direito Ambiental e Desenvolvimento Sustentável. v. 10, n. 20, Belo Horizonte, 2012.

BOFF, Leonardo. Ethos Mundial - Um consenso mínimo entre humanos. Rio de Janeiro: Sextante, 2003.

BOFF, Leonardo. Sustentabilidade: O que é, o que não é.Rio de Janeiro: Vozes, 2012.

BRASIL. Constituição de (1988) Constituição da República Federativa do Brasil. Brasília: Senado, 1988. Disponível em:

http://www.planalto.gov.br/ccivil_03/constituicao/constituicaocompilado.htm>. Acesso em: 21 abr. 2015.

BRENNAN, Andrew; LO, Yeuk-Sze.Environmental Ethics. Califórnia: The Stanford Encyclopedia of Philosophy, 2011. Disponível em:

$<$ http://plato.stanford.edu/archives/fall2011/entries/ethics-environmental/>. Acesso em: 08 mai. 2015.

COSTA, Beatriz Souza. Meio ambiente como direito à vida: Brasil, Portugal, Espanha. Belo Horizonte: Editora O Lutador, 2010.

ENRIQUEZ, Eugène. Instituições, poder e desconhecimento. In: ARAÚJO, J.N.G e CARRETEIRO, T. C. Cenários sociais e abordagem clínica. Tradução: Vanessa Andrade de Barros. São Paulo: Escuta, 2001.

FIORILLO, Celso Antonio Pacheco. Curso de Direito Ambiental Brasileiro. 14. ed. São Paulo: Saraiva, 2013.

LEFF, Enrique. Complexidade, Interdisciplinaridade e Saber Ambiental. In PHILIPPI JR, Arlindo et al. Interdisciplinaridade em Ciências Ambientais. São Paulo: Signus, 2000. p. 1951. Disponível em:

https://scholar.google.com.br/scholar?q=Complexidade,+interdisciplinaridade+e+saber+ambi ental\&hl=ptBR\&as_sdt=0\&as_vis=1\&oi=scholart\&sa=X\&ei=qgQ9VeOPHoSigwToo4CAB w\&ved=0CBoQgQMwAA\#. Acesso em: 09 mai 2015.

LEFF, Enrique. Epistemologia ambiental: tradução de Sandra Valenzuela; revisão técnica de Paulo Freire Vieira.- 5. ed. São Paulo: Cortez, 2010.

LIMA, Gustavo da Costa. Questão ambiental e educação: contribuições para o debate.

Campinas: Ambient. Soc, 1999. Disponível em:

<http://www.scielo.br/scielo.php?script=sci_arttext\&pid=S1414-

753X1999000200010\&lng=pt\&nrm=iso>. Acesso em: 09 maio. 2015. 
LOPES, Ana Maria D'Ávila. Da coexistência à convivência com o outro: entre o multiculturalismo e a interculturalidade. REMHU, Rev. Interdiscip. Mobil. Hum. Brasília, v. 20, n. 38, 2012. Disponível em:

<http://www.scielo.br/scielo.php?script=sci_arttext\&pid=S198085852012000100005\&lng=pt \&nrm=iso>. Acesso em: 29 abr. 2015.

MILARÉ, Édis. Direito do Ambiente: a gestão em foco: doutrina, jurisprudência, glossário. 7. ed. São Paulo: Revista dos Tribunais, 2011.

OST. François. A natureza à margem da lei, a ecologia à prova do direito. Tradução: Joana Chaves. Lisboa: Instituto Piaget, 1995.

PAULITSCH, Nicole da Silva; WOLKMER, Maria de Fátima Schumacher. Ética Ambiental e Crise Ecológica: reflexões necessárias em busca da sustentabilidade. Revista Veredas do Direito: Direito Ambiental e Desenvolvimento Sustentável.v. 8, n. 16, Belo Horizonte, 2011.

SILVA, José Afonso da. Direito ambiental constitucional. 10. Ed. São Paulo: Malheiros Editores LTDA, 2013.

SIQUEIA, Josafá Carlos de. Ética e meio ambiente. São Paulo: Edições Loyola, 2002. . Ética Sociambiental. Rio de Janeiro: PUC-Rio, 2009. 